\title{
Metastatic Tumours in Ovaries
}

\section{PRASENJIT DAS, NARENDER KUMAR, SIDDHARTHA DATTA GUPTA}

\section{INTRODUCTION}

The ovaries provide a fertile area for metastases and are the most commonly involved organs in the female genital tract, regardless of the location of the primary tumour. ${ }^{1}$ Around $5-10 \%$ of all adnexal masses detected on physical examination are metastatic tumours of the ovary (MTO), though incidence rates for secondary tumours in this organ rise as high as $40 \%$, depending on the geographical location. ${ }^{2}$

Metastatic tumours can be confused with primary tumours of the ovary. ${ }^{3,4}$ The reason for that is in the fact that the metastatic tumours have the histopathology similar to the primary ovarian tumours. ${ }^{5,6}$

Although it is difficult to estimate the percentage of metastatic ovarian tumours from extra-genital primary sites, the incidence has been reported to range between $7 \%$ and $12.5 \%{ }^{2,4}$ The gastrointestinal tract is the first site to be scanned. The breast is the second most important primary site. ${ }^{5}$ Because ovarian metastasis develops in advanced stages of extragenital organ tumours, it generally carries a poor prognosis.

By the incidence of secondary deposits, we may point out cancers of the colon, stomach, breast and endometrium, as well as lymphomas and leukemias. ${ }^{9-11,}{ }^{24}$ Ovarian metastases have been detected in $32-38 \%$ of breast cancer patients; 28 $35 \%$ of women with colorectal cancer; and $16 \%$ of women with genital tract tumours (endometrium, uterine cervix, vagina, vulva. ${ }^{25}$ Lately, special attention has been paid to mucinous tumours of the appendix, pancreas and biliary tract, which commonly spread to the ovary, resembling thus mucinous borderline tumour or mucinous ovarian carcinoma.${ }^{26}$ Other malignant epithelial tumours, but also sarcomas and blastomas, can too metastasize to the ovary, though such metastases are fairly rare. ${ }^{27}$ In a compilation by Olivier $\mathrm{M}$ et al (2007), incidences of metastatic ovarian tumours have been represented in the following table:

Table: Incidences of ovarian metastasis in different series [12-23]:

\begin{tabular}{|l|l|l|l|l|l|l|l|l|l|l|}
\hline $\begin{array}{l}\text { Primary } \\
\text { Site } \\
\text { (Ref) }\end{array}$ & $\begin{array}{l}\text { Greene } \\
\text { et al } \\
\mathbf{( 1 2 )}\end{array}$ & $\begin{array}{l}\text { Webb } \\
\text { al } \\
\mathbf{( 1 3 )}\end{array}$ & $\begin{array}{l}\text { Mazar } \\
\text { ret al } \\
\mathbf{( 1 4 )}\end{array}$ & $\begin{array}{l}\text { Demopoulos } \\
\text { et al } \\
\mathbf{( 1 5 )}\end{array}$ & $\begin{array}{l}\text { Gagnon } \\
\text { and Tetu } \\
\mathbf{( 1 6 )}\end{array}$ & $\begin{array}{l}\text { Fujiwara } \\
\text { a et al } \\
\text { (18) }\end{array}$ & $\begin{array}{l}\text { Yada- } \\
\text { Hashimoto } \\
\text { et al (19) }\end{array}$ & $\begin{array}{l}\text { Moore } \\
\text { et al } \\
\text { (20) }\end{array}$ & $\begin{array}{l}\text { Ayhan } \\
\text { et al } \\
\text { (21) }\end{array}$ & $\begin{array}{l}\text { Skimi } \\
\text { sda et } \\
\text { al (22) }\end{array}$ \\
\hline Breast & $42 \%$ & $31 \%$ & $46 \%$ & $32 \%$ & $64 \%$ & $13 \%$ & $9 \%$ & $5 \%$ & $27 \%$ & $75 \%$ \\
\hline Colorectal & $15 \%$ & $38 \%$ & $40 \%$ & $12 \%$ & & $4 \%$ & $7 \%$ & $19 \%$ & $18 \%$ & $75 \%$ \\
\hline Uterine & $18 \%$ & $12 \%$ & $16 \%$ & $14 \%$ & $26 \%$ & & $15 \%$ & & $64 \%$ & \\
\hline Uterin & $1 \%$ & $3 \%$ & $14 \%$ & $0 \%$ & & & $9 \%$ & & $4 \%$ & \\
\hline Others & $1 \%$ & $8 \%$ & $21 \%$ & $12 \%$ & $18 \%$ & $25 \%$ & $9 \%$ & $31 \%$ & $21 \%$ & $64 \%$ \\
\hline
\end{tabular}

Department of Pathology, All India institute of Medical Sciences, 
MTO are bilateral in $70 \%$ of the cases and present as multiple superficial or parenchymatous, mostly solid nodules of various sizes. Ovaries themselves can be normal in size, slightly enlarged, or sized more than 10 $\mathrm{cm}$ in diameter. The presence of implants on the surface of ovaries, multi-nodularity and intravascular tumour emboli are of use in the diagnosis of MTO which reaches ovaries via abdominal cavity or Fallopian tubes. ${ }^{24}$

Histopathologic appearance of most MTO is similar to the one in ovarian cancers. Differential diagnosis of primary and secondary malignant tumours of the ovary is difficult if it is based only on clinical and histopathologic characteristics of the tumour. Immunohistochemistry has an important role in differential diagnosis of primary and metastatic ovarian tumours, and thus in appropriate treatment administration and assessment of prognosis. $^{24}$

For convenience we can divide the metastatic tumours of the ovaries into 2 broad groups:

A. Metastasis from the gonadal organs.

B. Metastasis from the extra-genital organs.

\section{Krukenberg's tumour: (KT) :}

Defined by an ovarian carcinoma that contains a significant component (at-least $10 \%$ of the tumour area) of mucin-filled signet-ring cells typically lying within a cellular stroma derived from the ovarian stroma. Recently this term has been used inappropriately by some authors to include: all glandular carcinomas metastatized to the ovary or all metastatic ovarian carcinomas arising in gastrointestinal tract. Almost all the KTs are metastatic. ${ }^{25}$

This entity was first recognized by Paget, J. (1854) in Lectures on Surgical Pathology, as a distinctive form of ovarian tumour associated with mammary or gastric cancer of "fibrous hard" nature. However they did not opine whether the tumour was primary or secondary. Latter Krukenberg, F. et al (1896) identified 6 cases of Krukenberg's tumours containing signet ring cells. However he then erroneously identified these lesions as primary fibrosarcoma containing mucinous cells. ${ }^{26}$
This tumour can be seen in a wide age range varying from 13 to 84 years and $40 \%$ of the tumours are seen in $<40$ years of age [5].Clinically the patient may be asymptomatic or may present with abdominal swelling or pain in abdomen $(90 \%)$ or hormonal manifestations like post menopausal bleeding, hirsutism, virilization etc.

Krukenberg's tumours are bilateral tumour in 3/ 4 of the cases and often the involvement of the smaller ovary may be identifiable only on microscopical examination. And in $20-30 \%$ of cases the primary gastric carcinoma and the Krukenberg's tumour are diagnosed concurrently.

The modes of metastasis are: blood flow, lymphatic spread, trans-peritoneal spread [25].

Gross findings: $>80 \%$ of the krukenberg's tumour are bilateral, in comparison to $15 \%$ bilateral primary endometrial or mucinous tumours. The ovaries may be of normal size or sometimes may be $>10 \mathrm{~cm}$ in size. The cut surfaces are solid, firm fleshy, rubbery or vague nodular and grey-white to yellow in colour. Few smaller cystic cavities filled with mucinous material can be identified. Necrotic or haemorrhagic areas may be seen.

Microscopical findings: Microscopically these tumours are comprised mainly of epithelial and stromal components. Different histological patterns can be identified like- classical pattern tubular pattern, varied spectrum of glandular differentiation and miscellaneous or combined histological types [25]. Microscopically a pseudolobular pattern is identified with cellular periphery and edematous central part. Classically single mucin filled signet ring cells or groups, trabecular arrangement of cells are noted. The stromal component may resemble a ovarian fibroma and show storiform patterns. Cells with a clear vacuole and an eosinophilic center or bull's eye appearance can be seen. Where the eosinophilic material are usually positive for mucicarmine and negative for periodic acid Schiff stain [5].In tubular type of Krukenberg's tumour round or oblong tubules comprised of signet ring cells are seen. In tubule-glandular pattern glands lined by lat cells 
are usually appreciated. However in the latter type the stroma is pauci-cellular. Feathery degeneration of the collagenous stroma can be identified.

\section{Determination of unknown primary from ovarian metastatic lesions}

One of the most important clinical concerns is to identify the site of primary tumour from an ovarian metastatic lesion. And histopathological examination can be a great help in this matter apart from the radiological and endoscopic examinations. There have been wide arrays of antibodies which can be used by immunohistochemical examination to get an idea of an unknown primary lesion. ${ }^{30}$

Here the different combinations of immunohistochemical markers have been discussed:

\section{Usefulness of CK7/ Colon ovarian tumour antigen [COTA]:}

CK7 has been identified in various epithelial tumours including ovarian tumours. However it has not been detected in colon carcinomas. COTA have been detected both in ovarian and colonic primary carcinomas. ${ }^{31}$ In a study by Lee E S et al (1998) incorporating a cohort of primary ovarian, colonic and metastatic ovarian carcinomas from various primary sites of gastrointestinal tract, CK7 and COTA was identified in $95 \%$ and $50 \%$ of primary ovarian tumours respectively, CK7 was negative in $95 \%$ and in COTA was positive in $68 \%$ in primary colonic neoplasms. From this study the authors concluded that combined use of CK7 and COTA can differentiate primary ovarian from primary colonic carcinomas. However it should be kept in mind that, while using these combinations of IHC markers, it cannot detect metastatic lesions from a gastric primary, as many of the gastric carcinomas are negative for both CK 7 and COTA. ${ }^{31}$

\section{Usefulness of IHC markers in differentiating primary endometrial versus primary ovarian tumours:}

Approximately $15-30 \%$ of women with endometrioid ovarian carcinoma also have cancer of uterine corpus [5]. Distinguishing a primary ovarian from primary endometrial tumour is always a challenge to the histopathologist, especially when the histologies are similar but not exact (e.g., pure endometrioid versus endometrioid with welldifferentiated squamous differentiation, such as in adenoacanthoma) or if the tumour in the second organ is metachronous (i.e., occurring at a subsequent time). ${ }^{5}$ The problem is further exaggerated by the varying criteria used by different pathologists to distinguish metastatic from synchronous primary tumours. This distinction, however, is of great clinical importance because of the significantly better prognosis of patients with synchronous primary tumours. Though there are few morphological pointers to speculate the primary site from the following criterias, but study of the IHC markers can only be objective in this issue. The differentiating points are:

A. The presence of a pre-cancerous lesion is a strong morphological indicator of in-situ genesis. In the endometrium, these processes include endometrial hyperplasia, especially if atypical, or the recent and more narrowly defined lesion, endometrial intraepithelial neoplasia. ${ }^{3,5}$ Similarly presence of a potentially precancerous processes in the ovary such as endometriosis or a preexisting benign or borderline tumour of similar histological type suggests de novo development of the cancer in the ovary ${ }^{5}$

B. Different histological types of synchronous endometrial and ovarian tumours are also good evidence of independent primaries. However there are exceptions to this concept and difference of histology cannot be taken as sole criteria to differentiate between these lesions. About $15 \%$ to $25 \%$ of ovarian tumours with endometrioid histology are associated with a histologically similar lesion in the endometrium. ${ }^{5}$

C. Bilateralism and multifocal lesions over the ovarian serosa is also a pointer towards metastatic lesion to ovaries. ${ }^{5}$

D. Identification of tumour emboli in the lumen of the fallopian tubes also suggests metastasis. This is most often associated with serous tumours arising in the endometrium that implant on the ovary by retrograde 
Metastatic tumours from the gonodal organs in ovaries [5]:

\begin{tabular}{|l|l|ll|}
\hline Primary site & Incidence & Route of extension \\
\hline Endometrium & $35-40 \%$ & $\square$ & Lymphatic/vascular \\
& & $\square$ & Fallopian tube emboli \\
& & $\square$ & Invasion through myometrium \\
\hline Fallopian tube & $13 \%$ & $\square$ & Direct extension \\
& & $\square$ & Surface implantation \\
\hline Cervix & $3-10 \%$ & $\square$ & Direct \\
& & $\square$ & Lymphatic/vascular \\
\hline Other Uterine Tumour & Rare & $\square$ & Any of the above \\
\hline Vulva/vagina & Rare & $\square$ & Any of the above \\
\hline
\end{tabular}

Metastasis from the extra-genital organs:

\begin{tabular}{|l|l|l|}
\hline Primary site & Incidence & Sub-types/ specific site of origin \\
\hline Breast & $10 \%$ & Lobular-3.6\%, ductal-2.6\%, signet ring-1.8\% \\
\hline Stomach & $\begin{array}{l}70 \% \text { of } \\
\text { Krukenberg's }\end{array}$ & $\begin{array}{l}\text { Signet ring cells- } 41 \% \text {, intestinal type carcinoma } \\
\text { stomach } 17 \%\end{array}$ \\
\hline Intestine & $4-10 \%$ & Sites: Rectum/sigmoid colon-77\%, descending \\
\hline & & colon- $5 \%$, ascending colon- $9 \%$, caecum-9\% \\
\hline & & sub-types: Intestinal type-most common, signet \\
\hline Appendix & & ring $5.4 \%$, small cell-rare \\
\hline Carcinoid Tumour & $2 \%$ & $\begin{array}{l}\text { Intestinal adenocarcinoma Mucinous type } \\
\text { Low grade mucinous epithelial neoplasm }\end{array}$ \\
\hline & & Sites: appendix(most common), colon, stomach, \\
\hline Adrenal & $25-30 \%$ (autopsy series) & Neuroblastoma \\
\hline Malignant melanoma & $18 \%$ (autopsy series) & $95 \%$ bilateral \\
\hline Pulmonary \& & $5 \%$ (autopsy series) & Small cell carcinoma (most common) \\
\hline mediastinum & & Large cell undifferentiated \\
\hline & & Poorly differentiated adenocarcinoma \\
\hline Pancreas & rare & Mucinous tumour \\
\hline Gall bladder/bile duct & rare & Hepatocellular carcinomas \\
\hline Liver & Rare & \multicolumn{2}{|l}{} \\
\hline Kidney/urinary bladder & Rare & Rhabdomyosarcoma (most common), leiomyosarcoma \\
\hline Extragenital sarcomas & Rare & \\
\hline
\end{tabular}

transmission.

E. In a metastatic intestinal carcinoma, there is evidence of necrosis, the glands are poorly differentiated and squamous differentiation is not seen in these glands. Whereas in ovarian endometrioid carcinoma necrosis is not seen, the glands are well 
differentiated and squamous differentiation is not uncommon. ${ }^{5}$

However in many instances these criterias fail. Surprisingly, there is little literature exploring the utility of the well established ovarian cancer marker CA125 in diagnosing

synchronous primary tumours [5]. And in our experience many a times CA125 remains < 35IU/L and does not help in these situations.

In such a situation use of IHC markers are necessary to differentiate between these lesions.

Endometrioid carcinoma of ovary: Approximately $40 \%$ of primary ovarian carcinomas are estrogen receptor (ER) and/or progesterone receptor (PR) positive. They are also positive for CK7 (97\%), CK20 (13\%), EMA, vimentin $(31 \%)$, B72.3 (86\%), CEA $(30 \%)$ and OC-125 (76\%).

Endometrioid carcinoma of endometrium: The endometrial carcinomas are also positive for ER and PR (30-35\%). In addition it can be positive for $\mathrm{Bcl} 2(65 \%)$, Her2Neu, vascular endothelial growth factor (VEGF) protein and can show accumulation of p53 protein.

Molecular studies:

Many molecular studies were performed to see the difference of molecular profile between

The most common primary sites of metastasis are as follows:

\begin{tabular}{|l|l|}
\hline Primary sites & Incidences \\
\hline Stomach & $76 \%$ \\
\hline Colon and rectum & $11 \%$ \\
\hline Gall bladder/biliary tract & $3 \%$ \\
\hline Breast & $4 \%$ \\
\hline $\begin{array}{l}\text { Others (small intestine, appendix, pancreas, rarely } \\
\text { uterus, urinary bladder, renal pelvis }\end{array}$ & $6 \%$ \\
\hline
\end{tabular}

Table: Presumption of possible primary tumour based on $\mathrm{CK} 7 / \mathrm{CK} 20$ status

\begin{tabular}{|l|l|}
\hline IHC status & Possible primary sites \\
\hline CK7+/CK20+ & Pancreas, bile duct, urothelium, gastric carcinoma (30\%) \\
\hline CK7+/CK20- & $\begin{array}{l}\text { Lungs, breast, endothelium, ovary, thyroid, salivary gland, } \\
\text { mesothelium }\end{array}$ \\
\hline CK7-/Ck20+ & Large bowel (95\%), Merkle cell carcinoma, gastric adeno CA \\
\hline CK7-/CK20- & Adrenal cortex, liver, kidney, adrenal gland \\
\hline
\end{tabular}

\begin{tabular}{|l|l|l|}
\hline Primary Tumours & CK7 & CK20 \\
\hline Colonic adenocarcinoma & $16 \%$ & $94 \%$ \\
\hline Ovarian adeno-carcinoma & $97 \%$ & $13 \%$ \\
\hline Lung adeno-carcinoma & $100 \%$ & $4 \%$ \\
\hline Breast adeno-carcinoma & $97 \%$ & $6 \%$ \\
\hline Merkel cell carcinoma & $0 \%$ & $95 \%$ \\
\hline Lung small cell carcinoma & $20 \%$ & $1 \%$ \\
\hline
\end{tabular}


these two tumour types and it can be used when IHC cannot determine. the primary site. Expression of $W T 1$ has been sited as a marker of ovarian primary [5]. In a study by Irvin et al (2005) it has been shown that presence of $\hat{a}$ catenin mutation is a marker of primary tumours of both ovarian and endometrial tumours [32]. Copy number analysis (CNA) and gene expression profiling was performed showed LOH of chromosome $17 \mathrm{p}$ and $10 \mathrm{q}$ along with 30 separately identifiable genes in endometrial carcinomas including PTEN mutation. ${ }^{32}$

\section{Usefulness of $\mathrm{CK} 7$ and $\mathrm{CK} 20$ IHC profile to} determine possible primary site of tumours:

The diverse and unique expression of CK 7 and CK 20 in different epithelial carcinomas has been found to be useful in determining the primary sites of metastatic tumours in ovaries [33]. Usually expression of either of these markers in $>5 \%$ tumour cells taken as positive and the distribution and intensity of staining is determining factor. Combined use of these two markers help in narrowing down the differential diagnoses of a possible primary site.

However the patterns of this IHC expression are not so simple and considerable over-expression can be identified. Numerous studies shave been performed and shows a pattern of CK7/CK20 expression in the following common epithelial tumours:

CK7 expression has been identified in majority of the adenocarcinoma to some extent. The finding of CK 7 negativity has greater diagnostic value. When a carcinoma is CK7-negative, the differential diagnosis should include prostate, renal cell, neuroendocrine, hepatocellular, and adrenal carcinomas, carcinoid tumours, germ cell tumours, and squamous cell carcinomas of various origins with exception of cervical squamous cell carcinoma. Metastatic tumours from the uterine cervix are usually CK7 positive [33]. It should also be remembered that CK20 negativity not always rules out a colorectal primary. As shown in the table CK 20 positivity is seen in the majority of cases of colorectal adenocarcinoma and over $30 \%$ of cases of gastric adenocarcinoma. However, rectal adenocarcinoma de novo can be CK 7+/CK 20+ or CK7+/CK 20- [33]. Poorly differentiated carcinomas or right sided colon carcinomas can be CK20 negative. Pattern of staining can often be helpful, as in merkel cell tumour CK20 positivity is seen as a specific dot like positivity.

Usefulness of other IHC markers those can supplement CK7/CK20 panel [34-35]:

Actually many markers are there which can be used to specify the source of primary tumour precisely. Some examples can be given:

Breast carcinomas- $\mathrm{ER}+, \mathrm{PR}+$, Her2neu/ ERBB2+, GCDFP-15+, vimentin-

Colon carcinoma- K-ras+, CDX2+, â-catenin+, CEA+, CA125-,

Renal Clear Cell CA- CK7+, CD10-

Pancreatic \& bile duct CA- CA 19-9+, DPC4-, ER-, PR-

AdenoCarcinoma uterine cervix- ER-, PR-, p16+ (Exception-serous adeno-carcinoma ovary can be p16 positive).

Ovarian AdenoCarcinoma Vs Epithelioid Mesothelioma- calretinin-, keratin 5/6-, B72.3+, CA 19.9+, Leu-M1+.

Metastatic Endocervical ademcarcinoma1 (ECA) Vs Uterine CA (UEC)-

CEA-strong cytoplasmic and luminal + in ECAs $(100 \%)$ weak and luminal in UECs (up to $50 \%$ ), Vimentin + in UEC, ER/PR + in UEC, p16+ in ECA (serous CA can be + ), p53 protein + in $80 \%$ of uterine serous CA; only seen in $10-20 \%$ UEC

Appendicular adenocarcinoma- $\mathrm{CK} 18+$, CK20+, CEA+, CK7-, HAM-56-

\section{Intestinal carcinoid tumours-}

Chromogranin, synaptophysin, PGP 9.5, CK (dot +)

\section{Primary Mucinous Carcinoma versus Metastatic Colon Carcinoma}

Primary mucinous carcinomas are frequently positive for CK20 [5]; hence, CK20 cannot be used to distinguish these tumours from metastatic colon carcinoma. Cytokeratin 7 is more useful in this situation, as it is diffusely positive in ovarian carcinoma and negative or focally positive in colon carcinoma. Ovarian mucinous carcinoma is negative for â-catenin and positive for MUC5AC, whereas colon carcinoma shows a 
reverse pattern. CDX2 is a sensitive but nonspecific marker for colon carcinoma. HAM 56 is typical of a primary than the metastatic ovarian carcinoma. Metastatic tumours in addition are usually bilateral, small $(<10 \mathrm{~cm})$ and show frequent signet-ring cells. ${ }^{5}$

The presence of ovarian metastases is a sign of poor prognosis of the non-genital primary tumour. Surgical management is necessary both for diagnostic and for palliative purposes. Cytoreductive surgery is applied in a number of patients, aiming to prolong survival and to improve quality of life.

\section{REFERENCES:}

1. Arguello $F$, Baggs RB, Eskenazi AE, Duerst RE Frantz CN. Vascular anatomy and organ-specific tumour growth as critical factors in the development of metastases and their distribution among organs. Int $J$ Cancer 1991; 48: 583-90.

2. Moore RG, Chung M, Granai GO, Gajewski W, Steinhoff MM: Incidence of metastasis to the ovaries from nongenital tract tumours. Gynecol Oncol, 2004; 93: 87-91.

3. Yada-Hashimoto $N$, Yamamoto T, Kamiura $S$, Seino H, Ohira H, Sawai K, Kimura T, Saji F: Metastatic ovarian tumours: a review of 68 cases. Gynecol Oncol, 2003; 89: 314-317.

4. Ulbright TM, Roth LM, Stehman FB: Secondary ovarian neoplasia: a clinicopathologic study of 35 cases. Cancer, 1984; 53: 1164-1174.

5. Young RH, Path FRC, Scully RE: Metastatic tumours of the ovary. In: Blaustein's pathology of the female genital tract,Kurman RJ (Ed), pp 1063-1101, Springer-Verlag, New York, 2002.

6. Prat J, editor. Pathology of the ovary. Philadelphia: Saunders; 2004.

7. Singh N, Lowe D. Metastases in the ovary. In: Jakobs $I J$, Shepherd JH, Oram DH, Blackett AD, Lu-esley $D M$, Berchuck $A$, et al. editors. Ovarian cancer. $2^{n d}$ edition. Oxford: University Press; 2002. p. 85-9.

8. Young RH, Hart WR. Metastases from carcinoma of the pancreas simulating primary mucinous tumours of the ovary. A report of seven cases. Am J Surg Pathol 1989;13(7):748-56.

9. Petru E, Pickel H, Heydarfadai M, Lahousen M, Haas $J$, Schaider $H$, et al. Nongenital cancers metastatic to ovary. Gynecol Oncol 1992;44(1): 83-6.

10. Hann L, Lui D, Shi W, Bach A, Selland DL, Castieli M. Adnexal masses in women with breast cancer:cUS findings with clinical and histopathologic correlation. Radiology 2000;216:242-7.

11. Tornos $C$, Soslow $R$, Chen $S$, Akram M, Hummer AJ, Abu-Rustum N, et al. Expression of WT1, CA 125 and GCDFP-15 as useful markers in the differential diagnosis of primary ovarian carcinomas versus metastatic breast cancer to the ovary. Am J Surg Pathol 2005;29(11):1482-9.

12. Greene HJ, Grusetz MW, Mackles A: Subsequent second primary and metastatic cancer of the ovary. Clin Obstet Gynecol 1969;12: 972-979.

13. Webb MJ, Decker DG, Mussey E: Cancer metastatic to the ovary:Factors influencing survival. Obstet Gynecol 1975;45:391-396.

14. Mazur MT, Hsueh S, Gersell DJ: Metastases to the female genital tract. Analysis of 325 cases. Cancer 1984;53:1978-1984.

15. Demopoulos RI, Touger L, Dubin N: Secondary ovarian carcinoma: A clinical and pathological evaluation. Int J GynecolPathol 1987;6:166-175.

16. Gagnon Y, Tetu B: Ovarian metastases of breast carcinoma.A clinicopathologic study of 59 cases. Cancer 1989;64:892-898.

17. Petru E, Pickel H, Heydarfadai M, et al.: Nongenital cancersmetastatic to the ovary. Gynecol Oncol 1992;44:83-86.

18. Fujiwara K, Ohishi Y, Koike H, Sawada S, Moriya T, Kohno I:Clinical implications of metastases to the ovary. Gynecol Oncol 1995;59:124-128.

19. Yada-Hashimoto N, Yamamoto T, Kamiura $S$, et al.. Metastatic ovarian tumours: A review of 64 cases. Gynecol Oncol 2003;89: 314-317.

20. Moore $R G$, Chung $M$, Granai CO, et al.: Incidence of metastasis to the ovary from nongenital tract primary tumours. Gynecol Oncol 2004;93:87-91.

21. Ayhan A, Guvenal T, Salman MC, et al.: The role of cytoreductive surgery in nongenital cancers metastatic to the ovaries. Gynecol Oncol 2005;98:235241.

22. Skirnisdottir I, Garmo H, Holmberg L: Non-genital tract metastases to the ovaries presented as ovarian tumours in Sweden 1990-2003: Occurrence, origin and survival compared to ovarian cancer. Gynecol Oncol 2007;105:166-171.

23. Kiyokawa T, Young RH, Scully RE: Krukenberg tumours of the ovary: A clinicopathologic analysis of 120 cases with emphasis on their variable pathologic manifestations. Am J Surg Pathol 2006;30.

24. Young RH, Scully RE. Metastatic tumours of the ovary. In: Kurman RJ, editor. Blaustein's Pathology of the Female Genital Tract. 5th edition . New York: Springer-Verlag; 2002.p.1063-101.

25. Mandai M. Krukenberg tumour. CME J Gynaec Oncol. 2004; 4: 112-14.

26. Wright TC,Felix JC. Symptoms are bilateral masse. Contemporary OB/Gynar archive,1996. http:// www.drugtopics.com/be_core/content/journals/g/ data/1996/0900/g9a061.html

27. Prat J, Morice P. Secondary tumours of the ovary In: Tavassoli FA, Devilee P, editors. World Health Organization Classification of Tumours. Pathology 
and Genetics of Tumours of the Breast and Female Genital Organs.Lyon:IARC Press; 2003. p.193-6.

Ronnett BM, Kurman RJ, Shmookler BM, et al. The morphologic spectrum of ovarian metastases of appendiceal adenocarcino-mas: a clinico-pathologic and immunohistochemical analysis of tumours often misinterpreted as primary ovarian tumours or metastatic tumours from other gastrointestinal sites. Am J Surg Pathol 1997;21: 1144-55.

Householder, JeanMarie, Han, Aaron, Edelson, Mitchell I, Eager, JMichael, Rosenblum, Norman G. Immunohistochemical confirmation of pulmonary papillary adenocarcinoma metastatic to ovaries. Arch Pathol Lab Med. 2002;126:1101-1103.

30.

Lee E S, Cho H D, Kim I. The usefulness of CK7 and colon ovarian tumour antigen in differential diagnoses of primary and metastatic ovarian neoplasms. Korean J Pathol. 1998; 32: 201-7.

31. A. Guirguis, E. Elishaev, K. Timms, J. Reid, V. Abkevich, A. Gutin, J. Launchbury, K. Zorn, D. Deloia. Characterization of concurrent ovarian and endometrial carcinoma by copy-number analysis (CNA) and gene expression profiling (GEP). Clin Oncology, 2007 ASCO Annual Meeting Proceedings Part I. Vol 25, No. $18 S$ (June 20 Supplement), 2007: 10546.

32. Irving JA, Catasus L, Gallardo A, Bussaglia E, Romero M, Prat J. Synchronous endometrioid carcinomas of the uterine corpus and ovary: alterations in the beta-catenin (CTNNB1) pathway are associated with independent primary tumours and favorable prognosis. Hum Pathol 2005;36(6):60519.

33. Mittal K, Soslow R, McCluggage $W$ G. Application of Immunohistochemistry to Gynecologic Pathology. Archives Pathol Lab Medicine. 2008; 5 : 13.

34. Peiguo Chu, M.D., Ph.D., Emerald Wu, B.S., Lawrence $M$ Weiss, M.D. Cytokeratin 7 and Cytokeratin 20 Expression in Epithelial Neoplasms: A Survey of 435 Cases. Mod Pathol 2000;13(9):962972.

35. McCluggage $W G$, Young RH. Immunohistochemistry as a diagnostic aid in the evaluation of ovarian tumours. Semin Diagn Pathol. 2005;22 (1):3-32. 